\title{
Migración INDÍGENA EN LA FRONTERA COLOMBIA-ECUADOR: DEL CONFLICTO armado a la Agenda de Seguridad BINACIONAL
}

Sindy GonZÁLEz RodRígueZ*

\section{Resumen}

El repertorio de violencia que aún persiste en la zona de frontera colombo-ecuatoriana después de la firma del Acuerdo de Paz entre el Gobierno colombiano y la guerrilla de las Fuerzas Armadas Revolucionarias de Colombia-Ejército del Pueblo (FARC-EP) obliga a las comunidades indígenas de la región a migrar forzosamente hacia Ecuador, lo que causa una ruptura en su dinámica de migración ancestral y en su relación con su territorio al verse obligadas a abandonarlo. Esta situación de migración transfronteriza indígena reclama la atención de ambos gobiernos mediante la inclusión del fenómeno como un tema prioritario (issue) en la agenda pública binacional.

Palabras clave: acuerdo de paz, agenda binacional, conflicto armado, enfoque diferen- cial étnico, etnocidio, migración transfronteriza ancestral, migración transfronteriza forzada, pueblo indígena, territorio ancestral.

\section{INDIGENOUS MIGRATION ON COLOMBIA-ECUADOR BORDER: FROM ARMED CONFLICT TO THE BINATIONAL SECURITY AGENDA}

\section{Abstract}

The violence repertoire that persists along the border between Colombia and Ecuador, after the signing of the Peace Agreement between the Colombian government and the Revolutionary Armed Forces of Colombia (FARC-EP), forces indigenous communities

* Profesional en Relaciones Internacionales; magíster en Asuntos Internacionales. Funcionaria de Exportación - Bela Iacá Polpas de Frutas Industria E Comercio Ltda. (Petruz Fruity), (Brasil). [sindygozz@yahoo.es].

Recibido: 27 de marzo de 2018 / Modificado: 10 de mayo de 2018 / Aceptado: 27 de julio de 2018.

Para citar este artículo

González Rodríguez, S. (2018). Migración indígena en la frontera Colombia-Ecuador: del conflicto armado a la Agenda de Seguridad Binacional. opera, 23, 7-26.

DOI: https://doi.org/10.18601/16578651.n23.03 
to migrate across state limits. This situation causes a rupture in their ancestral migration dynamics, not to mention their relation with their territory since they are forced to abandon it. Transborder Indigenous Migrations demand attention from both administrations by including the subject as a priority Issue in the Binational Agenda.

Key words: Ancestral territory, armed conflict, binational agenda, ethnocide, ethnic differential approach, indigenous peoples, peace agreement, transborder indigenous migration.

El fenómeno de la migración, según la Organización Internacional para las Migraciones (OIM) (2017), abarca aproximadamente el $3,3 \%$ de la población global y es definido por la Organización de las Naciones Unidas para la Educación, la Ciencia y la Cultura (UNESCO) como: "el cruce del límite de una unidad política o administrativa durante un cierto periodo de tiempo mínimo, incluyendoel movimientode refugiados ${ }^{1}$, personas desplazadas, personas desarraigadas y migrantes económicos que se reubican territorialmente entre EstadosNación” (Al Rahi, 2017, p. 3).

Ahora bien, existe un tipo de migración que se da específicamente entre países que comparten un territorio fronterizo común, cuyos límites son más fáciles de cruzar por aquellas comunidades que se encuentran en la línea de frontera y es conocido como migración transfronteriza (Khoudour-Castéras, 2009, p. 243). Asimismo, autores como Morales (2003) la definen como aquella que se da entre países limítrofes con dos destinos principales: “a) localidades adyacentes a las fronteras y zonas de plantación; y b) las ciudades" (p. 54). Dicho fenómeno se ha dado de manera significativa entre Colombia y Ecuador, especialmente desde el primer Estado hacia el segundo, pues las dinámicas socioeconómicas, políticas y de conflicto han influido de forma directa en la dirección del flujo migratorio.

Por ejemplo, en el mes de diciembre de 2017, 30.230 colombianos entraron a Ecuador, mientras que solo 15.706 ecuatorianos ingresaron a Colombia (Migración Colombia, 2017). Asimismo, la Cancillería del Ecuador (2017b) anunció, mediante un comunicado, que hasta abril de 2017 eran 59.560 los refugiados colombianos en Ecuador; es decir, el 98,3\% de la totalidad que recibe este país (párr. 4).

La migración transfronteriza que se pretende analizar aquí tiene lugar entre los departamentos de Nariño y Putumayo (Colombia) y Carchi, Sucumbíos y Esmeraldas (Ecuador); zona colindante de $586 \mathrm{~km}$ de longitud que va desde el litoral pacífico hasta la selva amazónica, donde además se presenta una concentración considerable de población étnica compuesta por comunidades afros e indígenas.

\footnotetext{
1 La Convención sobre el Estatuto de los Refugiados de la ACNUR (1951) reconoce a los refugiados como "cualquier persona que tenga fundados temores de ser perseguida por motivos de raza, religión, nacionalidad, pertenencia a determinado grupo social u opiniones políticas, se encuentre fuera del país de su nacionalidad y no pueda o, a causa de dichos temores, no quiera acogerse a la protección de tal país; o que careciendo de nacionalidad y hallándose, a consecuencia de tales acontecimientos, fuera del país en donde antes tuviera su residencia habitual, no pueda o, a causa de dichos temores, no quiera regresar a él" (art. 1.2).
} 
Justamente, la población indígena ubicada en la zona de frontera representa una cantidad considerable, de acuerdo con los datos de la tabla 1.

Los pueblos indígenas, definidos por quien fuera el Relator Especial de la Subcomisión de Prevención de Discriminaciones y Protección a las Minorías de las Naciones Unidas, José R. Martínez Cobo (1982), son aquellos "que teniendo una continuidad histórica con las sociedades anteriores a la invasión y precoloniales que se desarrollaron en sus territorios, se consideran distintos de otros sectores de las sociedades que ahora prevalecen en esos territorios o en partes de ellos" (p. 5). Pueblos que, hasta el día de hoy, se encuentran asentados dentro de un territorio indígena ancestral ${ }^{2}$ ubicado a ambos lados de la frontera, como son los pueblos awá y pastos, entre los departamentos de Nariño, Esmeraldas y Carchi; y los kamentsá-kamsá, siona, kofán, y kichwa/ inga en Sucumbíos y Putumayo.
Dichos pueblos no han sido ajenos al fenómeno de migración transfronteriza, pues históricamente esta se ha presentado como parte de sus patrones culturales, ya que la movilidad de un lado a otro de la frontera es indispensable para llevar a cabo actividades de subsistencia como la caza, pesca, recolección de plantas para la medicina tradicional, actividades espirituales o simplemente para visitar a un familiar, lo que requiere que se trasladen de un Estado a otro para conseguirlo.

Ángeles Trujano puntualiza que ese movimiento tiene una connotación histórica y ancestral donde "personas de un mismo pueblo indígena dentro de su territorio ancestral, cruzan una frontera internacional" (2008, p. 15). Lo anterior ha desarrollado en estas comunidades una identidad binacional que, aunque no se trate de un reconocimiento jurídico de doble nacionalidad, sí nace de sus propias prácticas cotidianas de migración, y produce una forma de vida comunitaria y una homogeneización

TABLA 1. POBLACIÓN INDÍGENA FRONTERA COLOMBO-ECUATORIANA (APROXIMACIÓN)

\begin{tabular}{|l|l|l|l|}
\hline \multicolumn{1}{|c|}{ Colombia (Defensoría del Pueblo de Colombia - 2017) } & \multicolumn{2}{|c|}{ Ecuador (Censo Ecuador - INEC 2010) } \\
\hline Nariño & 154.776 personas & Esmeraldas & 15.000 personas \\
\hline Putumayo & 61.386 personas & Carchi & 5.594 personas \\
\hline & & Sucumbíos & 23.647 personas \\
\hline Subtotal & 216.162 personas & Subtotal & 44.241 personas \\
\hline \multicolumn{2}{|r|}{ Total: 260.403 personas aprox. } \\
\hline
\end{tabular}

Fuente: elaboración propia con datos proporcionados por la Defensoría del Pueblo (2017) y por el Censo de 2010 de la República de Ecuador (INEC, 2010).

2 Según el Convenio 169 de la Organización Internacional del Trabajo (огт) (1989), un territorio indígena es "la totalidad del hábitat de las regiones que los pueblos interesados ocupan o utilizan de alguna otra manera" (art. 13). 
cultural dentro de un mismo territorio, a pesar de que esté dividido por una frontera. Al respecto, se puede citar el testimonio de un miembro del pueblo awá:

Hemos vivido de flujos y de reflujos [...] de la costa arriba [en referencia a Ecuador] hacia la costa abajo [en referencia a Colombia] [...] la raya como decían los viejos no había, que la gente iba de lado a lado no solamente con sus cargas y sus plátanos, sino también con sus sangres [...] esta frontera nunca estuvo dividida (Salazar, 2006).

$\mathrm{Y}$ es que el territorio indígena ancestral, ubicado a ambos lados de la línea fronteriza que divide los dos Estados, es entendido, de acuerdo con el Convenio 169 de la Organización Internacional del Trabajo (оIт) (1989), como "la totalidad del hábitat de las regiones que los pueblos interesados ocupan o utilizan de alguna otra manera" (art. 13). Dicho territorio es un factor fundamental, quizá el más importante dentro de su cosmovisión, pues el territorio ancestral "constituye una base espiritual y material complementarias. Además de formar el espacio que liga a numerosas generaciones con los antepasados, donde se origina su propia historia ligada a la identidad" (Sánchez, 2007). Este precedente permite comprender que el territorio es un vínculo entre los indígenas y su pasado, presente y futuro, otorgándoles un sentido de unión, supervivencia, arraigo, identidad y pertenencia.

Sin embargo, la migración transfronteriza indígena tomó un cauce diferente, pues desde los inicios del conflicto armado en Colombia, y las economías criminales articuladas a este, se desplazaron los procesos históricos de mi- gración por un éxodo reactivo y forzado en el que los indígenas han venido buscando su supervivencia.

Se hace aquí necesario, entonces, precisar el sentido en el que se usa la noción de migración forzada. La orm la define como aquella que "describe un movimiento de personas en el que se observa la coacción, incluyendo la amenaza a la vida y su subsistencia, bien sea por causas naturales o humanas" (2006, p. 39); y en el caso de los pueblos indígenas, la migración forzosa de Colombia a Ecuador ha sido mayormente atribuida a las décadas de conflicto armado interno. En efecto, el conflicto que azotó a Colombia por más de cincuenta años, y el cual finalizó con la firma del Acuerdo Final para la Terminación del Conflicto y la Construcción de una Paz Estable y Duradera, suscrito en 2016 entre el Gobierno nacional y las FARC-EP, fue el factor de expulsión más antiguo y determinante, reconocido como componente que violenta la permanencia de los pueblos indígenas en su territorio ancestral.

Dicha postura ha sido reconocida por entidades del Estado colombiano como: el Registro Único de Víctimas (RUV) (2017) que constató que desde el primero de enero de 1985 hasta el primero de febrero de 2017 , 8'048.252 personas han sido víctimas durante y después del conflicto armado; el Centro de Memoria Histórica (2012) también documentó que entre los años 1958 y 2012, fueron 65.500 los casos de desaparición forzada y 220.000 los asesinatos correspondientes a población civil no combatiente, con una mayoría indígena. Asimismo, la Contraloría General de la República (2015), mediante una encuesta, confirmó que entre 1985 y 2015 el despojo 
de tierras, incluidos los territorios indígenas sagrados, llegó a ser de 7 millones de hectáreas (ONIC, 2017a, párr. 3).

Conjuntamente, la Corte Constitucional colombiana determinó en 2009 que algunos pueblos indígenas de la zona de frontera colombo-ecuatoriana, como los awá, siona, kofán, inga y kamentsá-kamsá, corrían riesgo de exterminio cultural y físico como consecuencia directa del conflicto armado interno, el cual había operado como la causa mayor de la migración forzada al haberse introducido por la fuerza dentro de territorios ancestrales indígenas (Auto 004, 2009). La actuación de grupos armados ${ }^{3}$ catalizó la migración forzada transfronteriza a través de hechos coercitivos recurrentes como asesinatos, masacres, amenazas y confinamientos a lo largo del cordón fronterizo colombo-ecuatoriano.

Ahora bien, en la etapa actual de posconflicto, aún subsisten dinámicas, tradicionales o mutadas, de conflictividad y violencia dentro de los territorios indígenas en la zona de frontera. Por ejemplo, en resguardos ${ }^{4}$ ubicados en el municipio de Tumaco, Narińo, sobre las riberas del río Patía, se continúan presentando disputas entre grupos armados ilegales como el Ejército de Liberación Nacional (ELN), el cual en febrero de 2017 empezó un proceso de paz con el gobierno colombiano, y las Autodefensas Gaitanistas de Colombia (AGC) por el control del territorio en torno al negocio del narcotráfico (ONIC, 2018a).

Los mencionados altercados violan derechos fundamentales de la población indígena como el principio de libre determinación de los pueblos que, siguiendo a Díaz Müller, es "un derecho de un tipo específico de colectividad humana, unida por la conciencia y la voluntad de construir una unidad capaz de actuar en función de un futuro común" (1991, p. 58), lo que denota la libertad de los indígenas en decidir en su territorio sobre diversos asuntos de consulta, control, responsabilidad y participación. Este principio es acogido no solo en la Constitución de Colombia (1991) mediante el artículo 9 y en la Constitución del Ecuador (2008) mediante el artículo 57, sino también en acuerdos internacionales como el Convenio 169 de la oit sobre Derechos de los Pueblos Indígenas y Tribales (1989) en los artículos 6, 15, 17, 22, 27 y 28; y en la Declaración de las Naciones Unidas sobre Derechos de los Pueblos Indígenas (2007) en los artículos 3 y 4 (Medina, 2017).

3 La Corte Constitucional de Colombia (2009) declaró que en el conflicto participaron organismos de seguridad del Estado, paramilitares y grupos guerrilleros, los cuales habían tenido una presencia activa en la región de frontera. Todos estos actores han estado vinculados a homicidios, masacres, bombardeos, combates, desapariciones y torturas perpetrados contra la población civil, especialmente la indígena, lo que los llevó a migrar forzosamente huyendo de la violencia, tanto en forma masiva como individual (Auto 004).

4 La Constitución colombiana de 1991 define a los resguardos indígenas como una "Institución legal y sociopolítica de carácter especial, conformada por una comunidad o parcialidad indígena, que con un título de propiedad comunitaria, posee su territorio y se rige para el manejo de este y de su vida interna, por una organización ajustada al fuero indígena o a sus pautas y tradiciones culturales" (Decreto 2164/1995, art. 21). 
Los grupos disidentes, aprovechando las zonas abandonadas por las FARC después de la firma del acuerdo de paz, siguen hasta el día de hoy generando altercados bélicos con el fin de controlar la población y el territorio del corredor del río Patía y Mataje mediante la implementación de economías ilegales como el narcotráfico y la minería ilícita (Defensoría del Pueblo, 2018). Y es que, según John Jairo Tapie, miembro del pueblo pasto: "en el departamento de Nariño (fronterizo con Ecuador), la paramilitarización ha aumentado, con la presencia de 17 grupos armados al margen de la ley, de cortes paramilitares y subversivos" (EFE-Ginebra, 2018a).

Lo anterior fue reiterado por la Defensoría del Pueblo (2017), que destacó las violaciones de los derechos humanos que se continúan perpetrando en la zona de frontera colomboecuatoriana, entre las que se encuentra, en primer lugar, la persecución (43,41\%); los homicidios ( $27,97 \%)$; el despojo de bienes $(27,75 \%)$; los actos terroristas (21,22\%); y el reclutamiento ilegal $(7,72 \%)$. La figura 1 muestra los datos mencionados.

El carácter sistemático de dichos repertorios de violencia activados sobre la población indígena analizada, y su impacto sobre su proceso histórico de migración ancestral se ve reflejado en varios hechos recientes. En primer lugar, se puede citar el asesinato de un miembro del pueblo Awá, Óscar Pai Pascal, quien recibió cuatro impactos de bala en diciembre de 2017, por dos hombres encapuchados en

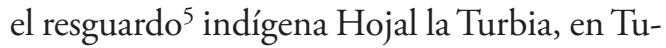
maco, Nariño. En el atentado también salió herido el hermano de la víctima, Alirio Pascal, y un menor de edad, ambos pertenecientes al pueblo indígena en mención (onIC, 2017b).

\section{FIGURA 1. VIOLACIONES DE LOS DERECHOS HUMANOS EN EL MARCO DEL POSCONFLICTO EN LA ZONA DE FRONTERA COLOMBO-ECUATORIANA (2017)}

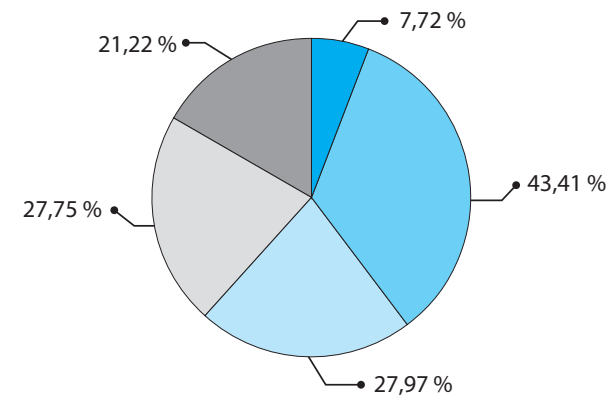

$\square$ Persecución $\quad \square$ Homicidios $\quad \square$ Despojo de bienes
$\square$ Actos terroristas $\quad \square$ Reclutamiento ilegal

Fuente: elaboración propia con datos proporcionados por el Informe sobre Zonas de Frontera de la Defensoría del Pueblo (2017).

Asimismo, el 22 de enero de 2018, debido a confrontaciones entre los grupos armados ilegales ELN y el Frente Oliver Sinisterra-una disidencia de las FARC- en el municipio de Cumbal (Nariño), alrededor de 60 indígenas de los pueblos pastos y awá migraron forzosamente hacia la población de Chical en la provincia ecuatoriana de Carchi, donde las víctimas de dicho desplazamiento fueron atendidas por el

\footnotetext{
5 Según el Decreto 2164 de 1995, de la Constitución colombiana de 1991, un resguardo indígena es una "Institución legal y sociopolítica de carácter especial, conformada por una comunidad o parcialidad indígena, que con un título de propiedad comunitaria, posee su territorio y se rige para el manejo de este y de su vida interna, por una organización ajustada al fuero indígena o a sus pautas y tradiciones culturales" (art. 21).
} 
personal del gobierno autónomo descentralizado de Chical (onic, 2018b).

Además de esto, la Consultoría para los Derechos Humanos y el Desplazamiento (CODHes) (2018) aseveró que solo en los primeros 28 días del ańo 2018, cuatro indígenas fueron asesinados y aproximadamente 1.616 fueron desplazados por amenazas, asesinatos y agresiones en departamentos como Nariño y Putumayo, lo que representa un escenario de exterminio físico y cultural de comunidades étnicas y campesinas que habitan en el cordón fronterizo (párr. 3).

El lado ecuatoriano de la zona de frontera también se ha visto afectado. Por ejemplo, según un comunicado de la ONIC (2018, párr. 3), el día 17 de marzo del presente año se presentaron enfrentamientos entre el ejército ecuatoriano y grupos armados ilegales en la vereda el Pan, sector Montañitas (Ecuador), que afectaron seriamente dos casas de familias awá al encontrarse en medio del fuego cruzado.

Otro hecho violento tuvo lugar el $23 \mathrm{de}$ marzo de 2018, en Mataje, provincia ecuatoriana de Esmeraldas, cuando, bajo el mando de alias Guacho, líder del grupo disidente Frente Oliver Sinisterra, se llevó a cabo el secuestro de los periodistas Javier Ortega, Paúl Rivas y Efraín Segarra, quienes fueron asesinados 18 días después (EFE-Ginebra, 2018b). Esta situación dejó un ambiente de pánico y terror en las comunidades que habitan en las cuencas del río Mira y Mataje, que en su mayoría pertenecen al pueblo awá.

A esto se suma que el día 4 de mayo de 2018 hubo una migración forzada de nueve familias, aproximadamente 40 personas, del Resguardo Indígena Awá de Piedra Sellada, en el municipio de Tumaco, debido a enfrentamientos de la fuerza pública y grupos armados ilegales en sus territorios. La comunidad aseguró que huyeron al escuchar los enfrentamientos y las bombas instaladas en medio del río Mira (ONIC, 2018c).

Un albergue temporal para las víctimas de dicha migración forzada ha sido el municipio ecuatoriano de San Lorenzo, en Esmeraldas, donde hasta el mes de abril de 2018 habían llegado 52 familias que reunían a 143 personas, quienes recibieron atención por parte de los ministerios ecuatorianos de Salud, Educación, Secretaría de Riesgos y Bienestar Social, el ACNUR y la OIM (OCHA, 2018).

A raíz de los actos reiterados de violencia, fuerzas militares y policiales de Colombia y Ecuador se instalaron en territorios indígenas awá, tanto del lado colombiano como ecuatoriano: en Tumaco, en los resguardos de Piedra Sellada y Chingüirito Mira, y en la comunidad indígena de Guadalito, contigua a Mataje, en Esmeraldas, para combatir a grupos armados ilegales en la zona de frontera. Debido a esta militarización, el portavoz de la Confederación de Nacionalidades Indígenas de Ecuador (CONAIE), Apawki Castro, se pronunció sobre la situación denunciando el establecimiento militar en territorios ancestrales "sin previo aviso o coordinación", lo que es considerado una violación de los derechos colectivos contemplados en la Constitución Ecuatoriana ${ }^{6}$ (EFE-Ginebra, 2018c).

6 La Constitución Política de la República del Ecuador (2008), Capítulo 5, sobre Derechos Colectivos, reconoce que "El Estado reconocerá y garantizará a los pueblos indígenas: ser consultados sobre planes y programas de 
Asimismo, la Unidad Indígena del Pueblo Awá (UNIPA) manifestó que la presencia de actores armados legales e ilegales en su territorio ancestral, además de poner en riesgo a la población, genera un desequilibro a nivel espiritual y emocional por la restricción a la movilidad, además del miedo y la intranquilidad a la cual se enfrentan diariamente (ONIC, 2018c).

Es preciso señalar que, adicional al daño que ocasiona la presencia militar dentro de una comunidad, esta desequilibra la relación de los pueblos con su territorio ancestral y promueve un eventual etnocidio ${ }^{7}$, es decir, una desaparición física y cultural de los conglomerados indígenas. Ciertamente, la agudización de actos violentos ha promovido la pérdida de lugares sagrados y la desconexión con las costumbres, los espacios y las tradiciones en medio de la ruptura del tejido social que ocasiona el fenómeno de la migración forzosa.

El panorama es todavía más desalentador debido a circunstancias ligadas a la presencia de grupos armados, como la explotación petrolera, la minería ilegal, la existencia de cultivos ilícitos y el narcotráfico. Y es que, desde la década de los noventa, los departamentos de Putumayo y Nariño han sido áreas con grandes cultivos de coca y amapola en Colombia, los cuales han generado ingresos monetarios a dichos grupos y a campesinos cultivadores, mientras invaden resguardos indígenas y amenazan la permanencia de la población.

Vale la pena anotar que la época más crítica de siembra de coca en Colombia fue en los años 1999-2000, con una concentración de 130.000 hectáreas sembradas, por lo cual se implementó el Plan Colombia (UnOdC, 2011). Este estaba focalizado, en principio, en los departamentos colombianos de Putumayo y Caquetá, como una estrategia para complementar los propósitos de la Iniciativa Regional Andina (IRA), la cual se encontraba dentro del marco del nuevo orden mundial tras los atentados del 11 de septiembre de 2001 a Estados Unidos.

El Plan Colombia, que se enfocó en la erradicación de los cultivos de uso ilícito a través de la militarización de la zona y de fumigaciones aéreas con el plaguicida glifosato ${ }^{8}$ desembocó, por un lado, en una profundización de la crisis social y humanitaria como respuesta al componente militar del Plan; y, por otro, en un empeoramiento en la salud de los habitantes debido a la contaminación del agua, los alimentos, la tierra y el aire, que afectó de manera directa la permanencia y subsistencia

prospección y explotación de recursos no renovables que se hallen en sus tierras y que puedan afectarlos ambiental o culturalmente; participar en los beneficios que esos proyectos reporten, en cuanto sea posible y recibir indemnizaciones por los perjuicios socioambientales que les causen" (art. 84).

7 El Instituto Interamericano de Derechos Humanos (IIDH) (2006) define el etnocidio como "la represión, deslegitimación o exterminio de los rasgos culturales de los pueblos indígenas y afrodescendientes aunque sus miembros sobrevivan como individuos. Provoca la muerte de la diversidad cultural, implica la lenta desaparición de la especificidad de los hombres y de los pueblos" (párr. 3).

8 El glifosato, comercializado por la multinacional estadounidense Monsanto, fue considerado por la Organización Mundial de la Salud (oms) como un pesticida "probablemente cancerígeno para el ser humano" (2015, p. 1). 
en la región de frontera ${ }^{9}$. Por ejemplo, entre el 70 y el $80 \%$ de los miembros del pueblo indígena kofán migraron forzadamente desde el departamento de Putumayo (Colombia) hacia Sucumbíos (Ecuador), evadiendo las intensas fumigaciones con glifosato en el 2001 (Defensoría del Pueblo, 2001).

Asimismo, en 2007, este mismo pueblo indígena sufrió la intoxicación de 49 de sus miembros debido a las fumigaciones, con enfermedades respiratorias y dermatológicas. Esta situación incrementó el fenómeno de migración forzada transfronteriza hacia poblaciones cercanas en Ecuador (Auto 004, 2009).

No fue hasta el año 2015, luego de que la Organización Mundial de la Salud (oms) lanzara un informe calificando el pesticida como cancerígeno, y años después, por demandas internacionales interpuestas por el Estado ecuatoriano por dańos ocasionados en su territorio, que el Gobierno de Colombia, con el apoyo del Consejo Nacional de Estupefacientes, decidió ponerle fin a las fumigaciones con glifosato (Indepaz, 2015).

Adicionalmente, en el Punto 4 del documento final del Acuerdo de Paz entre el Gobierno colombiano y las FARC, Solución al Problema de las Drogas Ilícitas ${ }^{10}$, se propuso la implementación de un Programa Nacional Integral de Sustitución (PNIS) que hiciera parte de la Reforma Rural Integral (RRI); la sustitución de cultivos ilícitos hacia otras actividades económicas; así como el respeto y la aplicación de los principios y las normas del Estado social de derecho y convivencia ciudadana (Alto Comisionado para la Paz, 2016).

Sin embargo, según el Informe de Monitoreo de Territorios afectados por Cultivos Ilícitos de 2016, los cultivos de coca en toda Colombia se incrementaron, en solo un año, un $56 \%$, pasando de 96.000 cultivos en 2015 a 146.000 en 2016, con Narińo y Putumayo como los dos departamentos donde existe mayor concentración de coca, con 42.627 y 25.162 respectivamente ${ }^{11}$ (UNODC, 2017). Por su parte, en Ecuador, de acuerdo con la Armada Militar Ecuatoriana (2018, párr. 2), el 22 defebrero de 2018 localizaron una plantación de coca de aproximadamente 1.000 plantas, en la comuna el Cauchal-San Lorenzo en la provincia de Esmeraldas.

Todo esto permite reconocer algunas consecuencias que trae la dinámica de migración transfronteriza forzada. Dada la interdependencia de los indígenas con su territorio, el despojo del mismo contribuye a la pérdida

9 Otros planes que intensificaron la confrontación armada se presentaron con más fuerza, cristalizándose en la política de "Defensa y Seguridad Democrática” (2003), reforzada por la aplicación del Plan Patriota (2004), el Plan Victoria (2006) y el Plan Consolidación (2007).

10 En el Acuerdo Final para la Terminación del Conflicto y la Construcción de una Paz Estable y Duradera (2016) se declaró que las autoridades y demás actores políticos deben reconocer el uso de la hoja de coca, por parte de los pueblos indígenas de Colombia, como parte de su cosmovisión e identidad cultural, pues en este caso los cultivos son para fines tradicionales.

11 Según la Oficina de las Naciones Unidas contra la Droga y el Delito (UNODc) (2017), en el caso de los resguardos indígenas, también se evidenció un incremento de 11.837 en 2015 a 15.665 en 2016, lo que significa un $32 \%$ de crecimiento anual. 
del espacio comunitario donde se desarrollan las actividades culturales y económicas tradicionales, su autonomía y justicia propia bajo su cosmovisión. A este respecto, la migración transfronteriza forzada de las comunidades indígenas aumenta, a la vez que se violenta su relación con el territorio ancestral debido a la ruptura del entorno propio y el impacto cultural, lo que desemboca en daños y afectaciones en diversos niveles, tal como lo muestra la tabla 2.

En este contexto, las migraciones transfronterizas, tomadas en cuenta desde un enfoque diferencial indígena ${ }^{12}$, constituyen un

TABLA 2. SITUACIÓN DE DERECHOS HUMANOS DE GRUPOS ÉTNICOS EN LA FRONTERA COLOMBO-ECUATORIANA

\begin{tabular}{|c|c|c|c|}
\hline Comunitarios & Culturales & Organizativos & Territoriales y ambientales \\
\hline $\begin{array}{l}\text { 1. Irrespeto por las autoridades } \\
\text { tradicionales }\end{array}$ & $\begin{array}{l}\text { 1. Impedimento a la } \\
\text { realización de rituales } \\
\text { espirituales de las } \\
\text { comunidades }\end{array}$ & $\begin{array}{l}\text { 1. Debilitamiento } \\
\text { de la unidad y } \\
\text { organización } \\
\text { social }\end{array}$ & $\begin{array}{l}\text { 1. Mal manejo del agua } \\
\text { potable y residuos } \\
\text { sólidos, que ocasiona } \\
\text { contaminación y } \\
\text { enfermedades }\end{array}$ \\
\hline 2. Bloqueo de remesas de alimentos & $\begin{array}{l}\text { 2. Debilitamiento } \\
\text { espiritual y cultural de las } \\
\text { comunidades }\end{array}$ & $\begin{array}{l}\text { 2. Ausencia del } \\
\text { cumplimiento de } \\
\text { reglamentos en } \\
\text { cada comunidad }\end{array}$ & $\begin{array}{l}\text { 2. Restricción a la } \\
\text { movilidad por causa } \\
\text { del tránsito de actores } \\
\text { armados legales e ilegales }\end{array}$ \\
\hline $\begin{array}{l}\text { 3. Ocupación de escuelas, viviendas } \\
\text { y centros comunitarios por parte de } \\
\text { actores armados legales e ilegales }\end{array}$ & $\begin{array}{l}\text { 3. Pérdida de la enseñanza } \\
\text { de la lengua }\end{array}$ & $\begin{array}{l}\text { 3. Irrespeto hacia } \\
\text { las máximas } \\
\text { autoridades } \\
\text { indígenas }\end{array}$ & $\begin{array}{l}\text { 3. Pérdida de la calidad } \\
\text { de los suelos, cultivos } \\
\text { y especies silvestres } \\
\text { por fumigaciones } \\
\text { indiscriminadas }\end{array}$ \\
\hline $\begin{array}{l}\text { 4. Pérdida de audición y secuelas } \\
\text { psicológicas }\end{array}$ & $\begin{array}{l}\text { 4. Aplicación de un modelo } \\
\text { de educación ajeno y } \\
\text { que no es semejante a la } \\
\text { identidad cultural }\end{array}$ & $\begin{array}{l}\text { 4. Estrategias de } \\
\text { aculturación y } \\
\text { sometimiento }\end{array}$ & $\begin{array}{l}\text { 4. Construcción de } \\
\text { carreteras sin consulta } \\
\text { previa o indemnización de } \\
\text { las familias afectadas }\end{array}$ \\
\hline \multirow[t]{2}{*}{$\begin{array}{l}\text { 5. Intoxicación y enfermedades por } \\
\text { contaminación de fuentes hídricas y } \\
\text { mal manejo de residuos sólidos }\end{array}$} & $\begin{array}{l}\text { 5. Pérdida de las prácticas } \\
\text { culturales propias de la } \\
\text { medicina tradicional }\end{array}$ & & \\
\hline & $\begin{array}{l}\text { 6. Uso de métodos y } \\
\text { medicamentos ajenos a la } \\
\text { cosmovisión indígena }\end{array}$ & & \\
\hline
\end{tabular}

Fuente: elaboración propia con base en datos proporcionados por el informe sobre las zonas de frontera de la Defensoría del Pueblo (2017).

12 Siguiendo a la Unidad para la Atención y Reparación Integral a las Víctimas (UARIV) (2014), este enfoque se refiere a un reconocimiento a la población indígena, que por sus características particulares de diversidad cultural, social e histórica, deben recibir un tratamiento especial en materia de ayuda humanitaria, atención, asistencia y reparación integral. 
tema obligatorio dentro de la Agenda Binacional de ambos gobiernos, pues se trata de un fenómeno que afecta a pueblos binacionales ubicados en ambos lados de la frontera, sobre un territorio ancestral que existe desde antes que la división política se llevara a cabo. Sin embargo, la Agenda Pública Binacional que, como lo afirman Cobb y Elder, consiste en una lista de issues o asuntos de interés que dos Estados han aceptado formalmente con atención seria y que han alcanzado un alto nivel de visibilidad (1972, p. 895), se ha llevado a cabo en el caso de Ecuador y Colombia, desde un estricto enfoque de seguridad.

Esta perspectiva surge como una respuesta antela internacionalización del conflicto armado colombiano, que en Ecuador traspasó los cordones fronterizos con la cadena internacional de las drogas, puesto que sus ciudadanos se vieron inmiscuidos en las plantaciones de coca de los departamentos del Putumayo y Nariño; en el tráfico de precursores químicos utilizados en dichas plantaciones y procesadoras; en el tráfico de estupefacientes y lavado de dinero (aprovechando la dolarización de su economía); tráfico de armas, municiones, explosivos y elementos de guerra (Morales, 2010).

Sin embargo, de acuerdo con Borja, dicha internacionalización no es simplemente el proceso de dispersión incontrolable del conflicto en sí mismo, sino que este también responde a una "decisión explícita y consciente" (2007, p. 72) de los Estados, es decir, es un proceso en el que se hace uso de estrategias voluntarias y deliberadas por parte de los actores políticos internos para construir alianzas con actores externos. Este fue el caso de la agenda política de Colombia con Estados Unidos, que desde 2001 estaba basada en términos de seguridad, siguiendo parámetros del nuevo orden mundial contra las drogas y el terrorismo, para la aplicación de planes conjuntos de injerencia militar y aspersiones aéreas para la erradicación de coca.

Por su parte, el enfoque político en la Agenda de Ecuador y Colombia también ha obedecido a decisiones gubernamentales. La implementación del Plan Colombia desde el ańo 2000, y la presencia militar estadounidense en la frontera norte ecuatoriana, amenazaban la soberanía territorial del Ecuador y a la nueva tendencia de unión latinoamericana en la región, por lo que la dirección del interés binacional era hacia la seguridad y defensa, dejando de lado el enfoque diferencial étnico.

Además, los bombardeos de 2008 por parte de las Fuerzas Armadas colombianas ${ }^{13}$, llevados a cabo con el fin de dar muerte al comandante de la guerrilla de las FARC Luis Edgar Devia, alias Raúl Reyes, provocó duras reacciones por parte del Gobierno ecuatoriano que interpuso una demanda contra Colombia ante la Corte Internacional de Justicia de La Haya (CIJ), y a romper las relaciones bilaterales entre los ańos 2008 y 2010. Entre las reclamaciones de Ecuador se encontraban: respetar la soberanía y la integridad de su territorio; impedir el uso de cualquier herbicida tóxico que pueda afectar a Ecuador; abstenerse de usar dichas sustancias tóxicas en o cerca de la frontera compartida; e indemnizar al Estado ecuatoriano por pérdidas y dańos ocasionados

13 Este operativo militar, también es conocido como "Operación Fénix” o "El ataque de Angostura”. 
por hechos internacionales ilícitos ${ }^{14}$ (Molano, 2013). Sin embargo, pese a estas tensiones, desde 2010, con el cambio de Gobierno en Colombia, hubo un restablecimiento del diálogo dentro del marco de la confianza mutua.

De igual forma, se retomaron las Comisiones de Buena Vecindad e Integración Colombia-Ecuador (CVICE), que fueron creadas a finales de los años ochenta, y que constituyen un mecanismo de diálogo político que promueve la integración, el desarrollo y la cooperación en la zona de integración fronteriza (ZIF $)^{15}$. Estas están conformadas por los ministros de Relaciones Exteriores, los secretarios ejecutivos de cada Estado, los jefes de misión, delegados de alto nivel por cada capítulo nacional, un representante delegado de los gobernadores o alcaldes de los departamentos de frontera, y un representante del sector productivo de cada Estado (Cancillería de Colombia, 2018a).

El compromiso por la integración de ambos Estados se ratificó en 2011 con la creación de seis comités técnicos binacionales para el mejor desarrollo de las actividades de las CVICE y diversificar el contenido de la Agenda Pública. Entre ellos se destacan el Comité de Asuntos Fronterizos, el Comité de Infraestructura y Energía, el Comité de Asuntos Ambientales, el Comité de Asuntos Económicos y Comerciales, el Comité Técnico Binacional (ств) del Acuerdo de Pesca Artesanal, el Comité de Asuntos Sociales y Culturales y el Comité de Asuntos Indígenas y Comunidades Negras, Plurinacionalidad e Interculturalidad; esta última instancia es el espacio propicio para abordar el fenómeno transfronterizo indígena.

Otro paso importante fue la conmemoración en 2012 de otro mecanismo de integración política, esta vez a nivel presidencial, conocido como los gabinetes binacionales, en los que ambos jefes de Estado se reúnen anualmente para evaluar el avance de los compromisos y proyectos que se encuentran en la Agenda Pública Binacional, que desde entonces se articula bajo los ejes temáticos de infraestructura y conectividad, asuntos fronterizos, asuntos sociales y culturales, asuntos económicos y comerciales, seguridad y defensa, y asuntos ambientales.

Sin embargo, los gabinetes binacionales, desde sus inicios, le han dado prioridad al eje de seguridad y defensa. Por ejemplo, haciendo un repaso por la historia de los gabinetes, el primero de ellos llevado a cabo en 2012, en Tulcán, Ecuador, se resaltó la conservación de

14 Molano (2013) señala que hubo una negociación con respecto a la demanda, por medio de la cual el Estado colombiano se comprometió a respetar la soberanía del vecino país, los derechos del medio ambiente y su población. Asimismo, mantener una distancia de $10 \mathrm{~km}$ de la frontera colombo-ecuatoriana al momento de las aspersiones; además de una indemnización de 15 millones de dólares dirigida al desarrollo socioeconómico de la frontera.

15 Senplades y DNP (2014) señalan que la zona de integración fronteriza (ZIF) comprende las provincias de Carchi, Esmeraldas, Imbabura, Napo y Sucumbíos en Ecuador; y los departamentos de Narińo y Putumayo en Colombia. La ZIF se establece como el espacio de integración de los intereses comunes de ambas naciones con el objeto de mejorar las condiciones de vida de la población de la frontera. 
mecanismos securitizados como la Comisión Binacional Fronteriza (COMBIfron) ${ }^{16}$, la cual permite una cooperación más estable en términos de fortalecer, nuevamente, la seguridad fronteriza. A la par, se destacaron temas como los pasos de frontera informales, las accionescívico militares binacionales, la lucha contra el narcotráfico, la trata de personas y el Programa de Acción Binacional para Fortalecer la Seguridad Fronteriza desarrollado por los ministerios de Defensa e Interior (Cancillería de Colombia, 2012).

$\mathrm{Al}$ año siguiente, en el segundo Gabinete, realizado en Ipiales, Nariño, se resaltan varios adelantos en cuanto a los compromisos de seguridad de la agenda anterior. Además, se hizo una instancia a las entidades encargadas con el fin de legalizar cuatro pasos de la frontera identificados, para fortalecer con "un enfoque integral" y de "soluciones duraderas" los 39 pasos no formales restantes ya identificados en la frontera común (Cancillería de Colombia, 2013). Otra iniciativa fue la Operación Progreso pues, en octubre de 2013, la policía de Colombia apoyó a la policía ecuatoriana en la incautación de un semisumergible en la costa de Esmeraldas que era usado para el tráfico de drogas hacia Centroamérica y luego Norteamérica. Además de esta operación también se realizaron un sinnúmero de acciones conjuntas para la captura coordinada de miembros de la guerrilla y de bandas criminales, la incautación de drogas, armas y contrabando, y el desmantelamiento de laboratorios para el procesamiento de base de coca (Cabrera, 2017).

En el tercer Gabinete, realizado el 17 de diciembre de 2014 en la provincia ecuatoriana de Esmeraldas, se registraron avances en cuanto a la presencia de las entidades de control que han permitido la formalización del paso transfronterizo de Chiles, Nariño (Colombia), Tufiño, Carchi (Ecuador), y en los compromisos para fortalecer la infraestructura que conecta El Carmelo (Ecuador) con La Victoria (Colombia), los cuales se proyectaban como dos nuevos pasos alternos a los de Rumichaca y San Miguel (Cancillería de Colombia, 2014a). De igual forma, en el Plan Operativo Anual Binacional de Seguridad ${ }^{17}$ y Defensa se estableció como propósito central continuar con la coordinación de las políticas binacionales en asuntos militares y policiales en las fronteras, adelantando e incrementando patrullajes para combatir el crimen en la zona de frontera.

En 2015, al celebrarse el IV Gabinete Binacional en la ciudad de Cali (Colombia), se trataron temas como el estrecho nivel de relacionamiento existente entre las fuerzas militares y policiales de los dos Estados, y los resultados en la lucha común contra la delincuencia organizada transnacional, el tráfico

16 De acuerdo con Bermeo y Pabón (2008), la Combifrom fue creada en 2006 como una cartilla de seguridad de ambos lados -unidades militares y de policía fronterizas de las repúblicas del Ecuador y Colombia- para evaluar y supervisar el cumplimiento de compromisos militares de seguridad fronteriza, con el propósito de evitar incidentes que afecten la seguridad y estabilidad de ambos Estados, como la criminalidad y el narcotráfico.

17 El Plan Operativo Anual Binacional de Seguridad Colombia-Ecuador fue firmado en Tulcán durante el Gabinete Binacional II de 2013, con el fin de fortalecer la cooperación de ambos Estados. 
ilícito de drogas y la lucha contra la minería ilegal. Los pasos de frontera Chiles-Tufiño, El Carmelo-La Victoria y Puerto el CarmenPuerto Ospina, fueron inspeccionados por las instituciones de los dos Estados para mantener la seguridad (Cancillería de Ecuador, 2015). Asimismo, los ministerios de Defensa de Colombia y Ecuador crearon una fuerza de tarea conjunta o Grupo Élite Fronterizo en marzo de 2016 para coordinar acciones contra el crimen organizado, el narcotráfico, la minería ilegal, la extorsión, y temas como la migración ilegal (El Tiempo, 2016).

Para el año 2017, el Gabinete Binacional tuvo lugar en Samborondón (Ecuador), donde fueron reconocidos los avances en materia de coordinación operacional e intercambio de la información con respecto a amenazas y factores de riesgo en la frontera común. Además, se reiteró el compromiso de ambos gobiernos con el fortalecimiento de mecanismos como las acciones cívicas binacionales, cuyo principal objetivo es brindar y garantizar bienestar y desarrollo a los pobladores de la frontera (Cancillería del Ecuador, 2017).

De igual manera, en la conmemoración del vi Gabinete Binacional que tuvo lugar en la ciudad colombiana de Pereira, el de febrero de 2018, se corroboró el cumplimiento del $90 \%$ de ejecución del Plan Operativo Anual Binacional del año anterior; la importancia de mecanismos como la combirRon que han permitido obtener resultados en la lucha contra la delincuencia organizada; y el fortalecimiento de unidades de inteligencia financiera de ambos Estados para prevenir actividades ilícitas como el lavado de activos, el financiamiento del terrorismo y los flujos ilícitos de capitales (Cancilleria de Colombia, 2018b).
Supuesto todo lo anterior, es innegable el avance que ha tenido la agenda gruesa de seguridad y defensa, aunque también es claro que el tema de migraciones transfronterizas indígenas no ocupa un lugar clave en la misma. En las declaraciones resultantes de las reuniones bilaterales de los últimos años-de 2012 a 2018-sí se le ha dado prioridad a cuestiones migratorias tales como: refugiados, trata de personas, legalización de pasos de frontera informales, promoción y protección de derechos de las personas migrantes, repatriación de presos, plan retorno y movilidad humana e integración. Sin embargo, no se examina desde un enfoque diferencial étnico o bajo un reconocimiento a la dinámica de migración ancestral indígena, que por sus características particulares de diversidad cultural, social e histórica para ambos Estados, debe recibir un tratamiento especial en materia de ayuda humanitaria, atención, asistencia y reparación integral.

Cabe resaltar que el tema de los indígenas en la frontera colombo-ecuatoriana cuenta, desde 2012, con un Comité exclusivo de Asuntos Indígenas y Comunidades Negras, Plurinacionalidad e Interculturalidad dentro del marco de las Cvice, que consiste en un espacio en el cual las instituciones estatales, los gobiernos locales y representantes de la sociedad civil de los pueblos o nacionalidades indígenas y comunidades afrodescendientes residentes de la ZIF estudian los temas relevantes y de interés para estos actores con el fin de contextualizar sus problemas locales y la búsqueda de soluciones (Cancillería de Colombia, 2014b). No obstante, el tema de las migraciones transfronterizas de indígenas no ha sido gestionado de manera bilateral por 
este comité ${ }^{18}$, que mediante sus actas serviría de insumo para la consolidación de la agenda binacional, debido principalmente a la falta de articulación de ambos Estados a la hora de proponer o dar a conocer el tema a los comités binacionales.

En entrevista el 17 de octubre de 2015, a María Camila Ascuntar, miembro del Comité Técnico Binacional de Asuntos Indígenas de las CVCE, declaró que las propuestas sobre los temas que serían incluidos en la Agenda Binacional no le corresponden a la cancillería de Colombia, sino que estas deben ser presentadas por las instituciones que tienen voz y voto dentro del Ств, es decir, los organismos públicos y privados binacionales y delegados de las comunidades indígenas que lo conforman. Los Ств no se encargan de proponer temas, estos solo gestionan las propuestas de dichas instituciones para que se puedan incluir en la agenda, teniendo en cuenta la viabilidad de las solicitudes y que sean de común acuerdo con el Ecuador.

En cuanto el tema de migraciones transfronterizas de indígenas en la frontera colombo-ecuatoriana, Ascuntar afirmó que "no ha habido la necesidad de tocarlo, porque no ha habido alguna propuesta al respecto, ni siquiera de los delegados de las comunidades indígenas $[. .$.$] nosotros abrimos un escenario$ político para transmitir las propuestas que tengan viabilidad, es decir, que cuenten con un cronograma concreto, con recursos, sean aterrizados, y de impacto binacional" (Ascuntar, 2015). A pesar de que las migraciones trans- fronterizas de indígenas cuenten con algunas de las condiciones afirmadas por la funcionaria del ств para que un tema sea viable, la falta de voluntad política consensual para presentar el proyecto y lograr su inclusión en la Agenda Pública Binacional es preponderante.

Ahora bien, en cuanto al Acuerdo de Paz entre el Gobierno colombiano y las FARC, en el punto 6.1.12, "Capítulo Étnico", se brinda un espacio a los intereses étnicos. En las consideraciones de dicho aparte se menciona que a los pueblos indígenas, como víctimas del conflicto armado, deben serle otorgadas garantías en el marco de sus intereses propios y cosmovisiones, con control sobre sus tierras y territorios. Esto es, que para alcanzar una paz estable y duradera, con un enfoque diferencial étnico, se debía haber contemplado el reconocimiento de sus prácticas territoriales ancestrales que, en este caso, tendrían que ver con la migración transfronteriza ancestral.

No obstante, aunque la inclusión de un capítulo étnico en los acuerdos de paz representa una oportunidad para emprender procesos que permitan la reconstrucción y el fortalecimiento del desarrollo y las condiciones de vida para las comunidades indígenas de Colombia y de la zona de frontera en cuestión, el riesgo de la no implementación de los compromisos no se eliminó por completo, especialmente si se tiene en cuenta que las poblaciones indígenas son las más excluidas en términos de cumplimiento de derechos y políticas diferenciadas (Betancur, 2016).

18 Solo se han llevado a cabo tres reuniones de este ств, una en 2012 y las otras en 2013 y 2014. 
Al respecto, Cabrera y Echandía afirman que el fracaso de algunas iniciativas previas de paz se debe a la incapacidad del Gobierno y las guerrillas para superar la incompatibilidad de sus expectativas en las negociaciones. También, la falta de apoyo de algunos sectores de la dirigencia en Colombia a nivel económico y político para alcanzar el acuerdo revela el temor de varios sectores a los cambios que trae la paz, así como una subestimación del impacto que tendría la degradación del conflicto en el caso de que las negociaciones fracasen (2017, p. 49).

Esta falta de apoyo político mencionada por los autores se evidencia en la exclusión y falta de interés sobre temas que abarquen políticas o planes de salvaguardia que sean acordes con la cosmovisión indígena y garanticen sus prácticas tradicionales de movilidad dentro de su territorio ancestral y su permanencia en el mismo. Es por ello que en este artículo se insta a las instituciones de orden binacional, organismos públicos y privados, miembros de comunidades indígenas y gobernantes a que haya voluntad política para proponer un cronograma concreto en materia de prevención y protección para los pueblos indígenas binacionales de la zona de frontera colombo-ecuatoriana, en concordancia con su cosmovisión y brindando el respeto al derecho de permanecer en su territorio y continuar con sus dinámicas milenarias de migración no forzosa.

De la misma manera, en épocas donde la construcción de la paz y la concordia son primordiales, se hace necesario incluir, con responsabilidad y compromiso, en el diálogo del posconflicto, la protección de estos conglomerados que hacen parte de la población tanto colombiana como ecuatoriana, los cua- les merecen el cumplimiento de los derechos a la vida, a la autonomía, al gobierno propio y la permanencia sobre su territorio, tal como están comprendidos en autos emitidos por la Corte Constitucional colombiana, la Constitución Política del Ecuador, y en acuerdos internacionales como la Convención 169 de la OIт y la Declaración de las Naciones Unidas sobre los Pueblos Indígenas.

La visibilización del componente étnico en la frontera es clave para superar la crisis humanitaria presente en Colombia y Ecuador. Para lograr un camino de paz en la región se requiere un cambio en el desarrollo de los temas o issues comprendidos en la Agenda Pública Binacional, y la inclusión de las migraciones transfronterizas desde una perspectiva indígena representaría un primer paso para adoptar políticas públicas que, con el apoyo conjunto de ambos Estados, podrían llevar a soluciones sostenibles en la materia y responder efectivamente a los retos del posconflicto, para así salvaguardar física, espiritual y culturalmente a dichos pueblos.

\section{REFERENCIAS}

Alto Comisionado de las Naciones Unidas para los Refugiados (ACNUR) (1951). Convención sobre el Estatuto de los Refugiados. Ginebra: Naciones Unidas.

Alto Comisionado de las Naciones Unidas para los Refugiados (ACNUR) (2001). Compilación sobre desplazamiento forzado. Normas, doctrinas y Jurisprudencia nacional e internacional. Bogotá: ACNUR.

Alto Comisionado de las Naciones Unidas para los Refugiados (ACNUR) (2012). La Protección de los 
refugiados y el papel del ACNUR. Recuperado de http://www.acnur.org/fileadmin/Documentos/ Publicaciones/2012/11196.pdf

Al Rahi, M. (2017). International Migration Seen from a Mediterranean Perspective [La migración internacional vista desde una perspectiva mediterránea]. Roma: Sapienza.

Alto Comisionado para la Paz (2016). Acuerdo final para la terminación del conflicto y la construcción de una paz estable y duradera. Bogotá: Gobierno de Colombia.

Amaya, C. (2009). Impacto del conflicto armado en la frontera colombo-ecuatoriana y las implicaciones en sus relaciones diplomáticas a partir de la implementación del Plan Colombia hasta diciembre de 2009. Bogotá: Biblioteca del Centro de Recursos de Apoyo al Aprendizaje e Investigación (CRAI).

Amnistía Internacional (2018). Colombia 2017/2018. Londres: AI.

Ángeles Trujano, C. Y. (2008). Rutas indígenas: un marco para comprender la migración indígena. Ginebra: oIM.

Armada del Ecuador (2018). Armada del Ecuador localizó una plantación de hojas de coca en la comunidad El Cauchal, provincia de Esmeraldas. Quito, Ecuador.

Ascuntar, M. C. (17 de octubre de 2015). Inclusión del tema migraciones transfronterizas indígenas en la agenda pública binacional (S. González, entrevistador).

Bermeo, D. y Pabón, N. (2008). Las relaciones de seguridad entre Colombia y Ecuador: una nueva construcción de confianza. RESDAL, 13-14.

Betancur, A. C. (2016). El acuerdo de paz y los derechos territoriales indígenas y afrocolombianos. Revista Semillas, 65/66

Borja, S. (2007). La internacionalización del conflicto armado después del 11 de septiembre: ¿̨a ejecución de una estrategia diplomática hábil o la simple ocurrencia de lo inevitable? Revista Colombia Internacional, 65

Cabrera, I. (2017). Iniciativas bilaterales de seguridad entre Colombia y sus vecinos (2010-2016). En I. Cabrera y C. Echandía (2017). Madurez para la paz. Evolución de la territorialidad y las estrategias en el conflicto armado colombiano. Bogotá: Universidad Externado de Colombia.

Cabrera, I. y Echandía, C. (2017). Madurez para la paz. Evolución de la territorialidad y las estrategias en el conflicto armado colombiano. Bogotá: Universidad Externado de Colombia.

Cancillería de Colombia (11 de diciembre de 2012). Declaración Presidencial del Primer Gabinete Binacional Ecuador-Colombia. Recuperado de http://www.cancilleria.gov.co/newsroom/news/ declaracion-presidencial-del-primer-gabinetebinacional-ecuador-colombia

Cancillería de Colombia (2013). Declaración conjunta presidencial Colombia-Ecuador, al término del segundo Gabinete Binacional. Ipiales, Colombia.

Cancillería de Colombia (8 de diciembre de 2014a). Cancillería. Ministerio de Relaciones Exteriores de Colombia. Recuperado de https://www. cancilleria.gov.co/politica/comision-vecindadcolombia-ecuador

Cancillería de Colombia (2014b). Encuentro Presidencialy III Gabinete Binacional Ecuador-Colombia. Esmeraldas, Ecuador.

Cancillería de Colombia (2014c). Integración fronteriza con Brasil, Ecuador y Perú. Recuperado de http://www.cancilleria.gov.co/en/integracionfronteriza-brasil-ecuador-y-peru

Cancillería de Colombia (2018a). Comisión de Vecindad e Integración Colombia-Ecuador. Recuperado de www.cancillería.gov.co http://www.cancilleria. gov.co/en/node/12422 
Cancillería de Colombia (2018b). Declaración de Pereira del VI Gabinete Binacional Colombia-Ecuador y logros de la reunión. Pereira.

Cancillería de Ecuador (2015). Declaración del encuentro presidencial y IV Gabinete Binacional ColombiaEcuador. Santiago de Cali.

Cancillería del Ecuador (2017). Declaración del encuentro presidencial y $V$ Gabinete Binacional EcuadorColombia. Guayas, Ecuador.

Cancillería del Ecuador (2017). Foro de análisis sobre los avances y desafios en cuanto a Movilidad Humana. Quito.

Comisión Económica para América Latina y el Caribe (CEPAL) (2010). Migración y salud en zonas fronterizas: Colombia y el Ecuador. Santiago de Chile: CEPAL.

Cobb, R. y Elder, C. (1972). Participation in amercian Politics: The Dynamics of Agenda-Building. Baltimore: The Johns Hopkins University Press.

Consultoría para los Derechos Humanos y el Desplazamiento (CODHES) (2018). Alerta por grave situación de etnocidio en Colombia. Bogotá: CODHes.

Corte Constitucional de Colombia (2009). Auto 004 de 2009. Bogotá.

Currea, A. T. (2012). Dilemas y perspectivas de la relación de Colombia y Ecuador. En S. Jost, Los desafios regionales de Colombia (pp. 599-611). Bogotá: Opciones Gráficas Editores Ltda.

Defensoría del Pueblo (2001). Fumigaciones y proyectos de desarrollo alternativo en el Putumayo. Bogotá: Defensoría del Pueblo.

Defensoría del Pueblo. (2017). Informe defensorial sobre las zonas de frontera. Bogotá: Defensoría del Pueblo.

Defensoría del Pueblo (9 de enero de 2018). Defensoría del Pueblo alerta por grave situación de riesgo en Tumaco y la cuenca del río Patía, en Nariño. Recuperado de http://www.defensoria.gov.co/es/nu-
be/noticias/6981/Defensor\%C3\%ADa-del-Pueblo-alerta-por-grave-situaci $\% \mathrm{C} 3 \% \mathrm{~B} 3 \mathrm{n}$-de-riesgo-en-Tumaco-y-la-cuenca-del-r \%C3 \%ADoPat \%C3\%ADa-en-Nari \%C3 \%B1o-TumacoPolicarpa-Defensor \%C3 \%ADa-SAT-alertastempranas-Nari \%C3\%B1o.htm

Díaz Muller, L. (1991). Las minorías étnicas en sistemas federales: ¿Autodeterminación o autonomía? En Aspectos nacionales e internacionales sobre derecho indigena. Ciudad de México: Instituto de Investigaciones Jurídicas-Universidad Nacional Autónoma de México.

Duro, R. (2002). Plan Colombia o la paz narcótica. Revista OPERA, 2 (2), 87-116.

EFE-Ginebra (13 de abril de 2018). El asesinato de los periodistas de Ecuador estremece la reunión de medio año de la SIP. Recuperado de https://www. efe.com/efe/america/sociedad/el-asesinato-delos-periodistas-ecuador-estremece-la-reunionmedio-ano-sip/20000013-3583448

EFE-Ginebra (4 de mayo de 2018). Indígenas de Colombia denunciaron aumento de agresiones tras acuerdo de paz. Recuperado de https://www.el-carabobeno. $\mathrm{com} /$ indigenas-de-colombia-denunciaron-aumento-de-agresiones-tras-acuerdo-de-paz/

EFE-Ginebra (18 de abril de 2018). La Conaie pide garantias de DDHH en frontera con Colombia. Recuperado de https://ww2.elmercurio.com. ec/2018/04/18/la-conaie-pide-garantias-deddhh-en-frontera-con-colombia/

El Tiempo (23 de marzo de 2016). Colombia y Ecuador crearán un grupo élite fronterizo. El Tiempo.

Garzón, O. (2012). Migración forzada en la zona suroccidente: el caso del pueblo indigena de "Los Pastos”. Quito: Universidad Andina Simón Bolívar .

Gleditsch, K. (2007). Transnational Dimensions of Civil War. Essex: Department of Government, 
University of Essex \& Centre for the Study of Civil War, PRIO.

IGWIA (2012). Pueblos indigenas en aislamiento voluntario y contacto inicial. Instituto de Promoción Estudios Sociales (IPES).

Instituto de Estudios para el Desarrollo y la Paz (INDEPAZ) (2015). Derecho de petición sobre no uso de glifosato en Colombia. Bogotá: INDEPAZ.

Instituto Nacional de Estadística y Censos (INEC) (2010). Población y demografía del Ecuador. Quito: INEC.

Instituto Interamericano de Derechos Humanos (IIDH) (2006). Etnocidio. San José: IIDH.

Khoudour-Castéras, D. (2009). Efectos de la migración sobre el trabajo infantil en Colombia. Revista de Economía Institucional, 11 (20), 229-252.

Manjarrés, A. (2010). Análisis de la repercusión del conflicto interno colombiano en el plano internacional: las relaciones diplomáticas colombo-ecuatorianas en el periodo 2004-2008. Bogotá: Universidad Colegio Mayor de Nuestra Señora del Rosario. Martínez Cobo, J. (1982). Informe Martínez Cobo. Estudio del problema de la discriminación contra las poblaciones indigenas. Ginebra: United Nations - Economic and Social Council.

Medina, B. (2017). Autodeterminación de los pueblos indigenas: sus propias normas y sistemas politicos. Caracas: Aministía Internacional. Recuperado de https://www.amnistia.org/ve/ blog/2017/05/2472/derecho-a-la-autoderminacion-de-los-pueblos-indigenas

Mejía, W., García, C., Hernández, G. y Murillo, A. (2009). Movilidad humana en dos zonas de la frontera colombo-ecuatoriana: Ipiales-Tulcan y San Miguel- Lago Agrio. Bogotá: Grupo de Investigación en Movilidad Humana Red Alma Máter. Migración Colombia (2017). Boletín Migratorio 2017. Bogotá: Ministerio de Relaciones Exteriores.
Molano, A. (20 de octubre de 2013). El acuerdo entre Colombia y Ecuador: glifosato, secretos y contradicciones. Razón Pública. Recuperado de https:// www.razonpublica.com/index.php/politicay-gobierno-temas-27/7144-el-acuerdo-entrecolombia-y-ecuador-glifosato,-secretos-y-contradicciones.html

Morales, A. (2003). Globalización y migraciones transfronterizas en Centroamérica. Red de Revistas Científicas de América Latina y el Caribe, España y Portugal.

Morales, A. (2010). Migración y salud en zonas fronterizas: Colombia y Ecuador. Santiago de Chile: Cepal.

Oficina para la Coordinación de Asuntos Humanitarios (осна) (2018). América Latina y el Caribe: panorama humanitario mensual - Continúan Desplazamientos. Ginebra: OCHA-ONU.

Organización Internacional para las Migraciones (OIM) (2006). Glosario sobre migración. Ginebra: OIM. Organización Internacional del Trabajo (огт) (1989). Convenio 169 sobre Pueblos Indigenas y Tribales en paises independientes. Ginebra: OIT.

Organización Nacional Indígena de Colombia (ONIC) (2007). Memorias de los encuentros de fronteras realizados por la Organización Nacional Indígena. Bogotá: ONIC.

Organización Nacional Indígena de Colombia (ONIC) (2017). El proceso de pazy las víctimas del conflicto armado. Bogotá: ONIC.

Organización Nacional Indígena de Colombia (ONIC) (10 de diciembre de 2017). Otro indígena awá asesinado y uno herido en tiempos de paz, en inmediaciones del corregimiento de Llorente, municipio de Tumaco, Nariño. Recuperado de http://www. onic.org.co/comunicados-regionales/2216-otroindigena-awa-asesinado-y-uno-herido-en-tiem- 
pos-de-paz-en-inmediaciones-del-corregimiento-de-llorente-municipio-de-tumaco-narino

Organización Nacional Indígena de Colombia (ONIC) (2018). Crisis humanitaria en los resguardos indigenas awá que están ubicados en el municipio de Tumaco. Bogotá: ONIC.

Organización Nacional Indígena de Colombia (ONIC) (5 de mayo de 2018). Familias awá de por lo menos cinco resguardos desplazados y confinados en Nariño. Recuperado de http://www.onic.org. co/comunicados-onic/2365-familias-awa-depor-lo-menos-cinco-resguardos-desplazadosy-confinados-en-narino

Organización Nacional Indígena de Colombia (ONIC) (23 de enero de 2018). Pueblos Indígenas seguimos contando desplazamientos, confinamiento y muertos por confrontaciones armadas en nuestros territorios. Recuperado de http://www.onic. org.co/noticias/2254-pueblos-indigenas-seguimos-contando-muertos-y-desplazamientos-porconfrontaciones-armadas-en-nuestros-territorios

Organización Mundial de la Salud (oms) (marzo de 2015). Evaluation of five organophosphate insecticides and herbicides. IARC Monographs, 112. Lyon: International Agency for Research on Cancer.

Rivadeneira, F. (2001). Las relaciones colombo-ecuatorianas. En M. Ardila, Colombia y la seguridad hemisférica. Bogotá: Universidad Externado de Colombia, Facultad de Finanzas, Gobierno y Relaciones Internacionales.

Salazar, G. (2006). Cruzando la raya: dinámicas socioeducativas e integración fronteriza. (C. Walsh y L. Santacruz, entrevistadores)
Sánchez, E. (2007). Los pueblos indigenas en Colombia. Derechos, politicas y desafíos. Bogotá: ACNUR.

Santacruz, J. (2012). Alcance y limitaciones de la política bilateral migratoria entre Colombia y Ecuador. Estudio de caso: migraciones de colombianos a las poblaciones fronterizas del Ecuador. Periodo 2002-2010. Bogotá: Universidad Colegio Mayor de Nuestra Señora del Rosario, Facultad de Relaciones Internacionales.

Senplades y DNP (2014). Plan Binacional de Integración Fronteriza Ecuador-Colombia 2014-2022. Quito: Senplades y DNP.

Sistema de Información Ambiental Territorial de la Amazonía Colombiana (sIATAC) (2015). Departamento del Putumayo. Recuperado de http:// siatac.co/Atlas/putumayo.html

unesco (s. f.). Migrant/Migration [Migrante/Migración]. Recuperado de http://www.unesco.org/ new/en/social-and-human-sciences/themes/ international-migration/glossary/migrant/

Unidad para la Atención y Reparación Integral a las Víctimas (UARIV) (2014). Decreto 2569 de 2014. Bogotá: Departamento Administrativo para la Prosperidad Social.

Oficina de las Naciones Unidas contra la Droga y el Delito (Unodc) (2011). Colombia. Monitoreo de cultivos de coca 2011. Bogotá: UNODC.

Oficina de las Naciones Unidas contra la Droga y el Delito (unOdC) (2017). Monitoreo de territorios afectados por cultivos ilícitos 2016. Bogotá: UNODC. 